\title{
Association Of Diabetes With Sleep Duration and Quality in Urban and Rural Cameroonian Community Dwellers
}

\section{Elysée Claude BIKA LELE}

Medical Research Center, Institute of Medical Research and Medicinal Plants Studies; Cameroon Heart Foundation https://orcid.org/0000-0003-2528-9122

Jacques Narcisse DOUMBE

Faculty of Medecine and Pharmaceutical Sciences, University of Douala, Douala - Cameroon;

Laquintinie Hospital, Douala, Cameroon

\section{Philippe VAN DE BORNE}

ULB-Erasme Hospital, Free Brussels University, Brussels, Belgium

\section{Thierry MESSOMO}

Faculty of Medicine and Pharmaceutical Sciences, University of Douala, Douala - Cameroon

\section{EDISARI MBANGO}

Faculty of Medicine and Pharamceutical Sciences, University of Douala, Douala - Cameroon; Gynecoobstetric and Paediatric Hospital, Douala, Cameroon

\section{Michel HERMANS}

Endocrinology and Nutrition Unit, Cliniques Universitaires St-Luc, Université Catholique de Louvain, Brussels, Belgium

Jean Paul DEGAUTE

ULB-Erasme Hospital, Free Brussels University, Brussels, Belgium

\section{Marc LEEMAN}

ULB-Erasme Hospital, Free Brussels University, Brussels, Belgium

\section{Hugo Bertrand MBATCHOU}

Faculty of Medicine and Pharamaceutical Sciences, University of Douala, Douala - Cameroon; General Hospital Douala, Cameroon

\section{William NGATCHOU}

Faculty of Medicine and Pharamaceutical Sciences, University of Douala, Douala - Cameroon

\section{Daniel LEMOGOUM ( $\nabla$ dlems2002@yahoo.fr)}

https://orcid.org/0000-0001-6701-8764

\section{Research article}

Keywords: sleep quality, sleep duration, diabetes, urban, rural 
Posted Date: September 10th, 2019

DOI: https://doi.org/10.21203/rs.2.14189/v1

License: (c) (i) This work is licensed under a Creative Commons Attribution 4.0 International License. Read Full License 


\section{Abstract}

Background Sleep disorders are known to be linked with numerous cardiovascular co-morbidities like diabetes. The prevalence and impact of sleep quality and duration on diabetes in the Cameroonian population is not well established. The aim of our study was to evaluate the separate and combined roles of sleep duration and quality on diabetes mellitus in the urban and rural Cameroonian population.

Methods This was a cross-sectional prospective survey conducted in 249 rural and 250 urban community dwellers in Cameroon aged 18 years and older. Sleep duration (SD) and quality were self-reported using the Pittsburg Sleep Quality Index (PSQI). Poor sleep quality was considered for PSQI score $>5$ and short SD was considered $\leq 6 \mathrm{~h}$. Diabetes mellitus was considered for fasting blood glucose $\geq 126 \mathrm{mg} / \mathrm{dL}$ and/or being on glucose-lowering medication(s). Multivariable logistic regression was used to determine the association of sleep duration and quality with diabetes.

Results mean age was $36 \pm 12$ years with $39.1 \%$ male participants. Frequency of diabetes was $8.2 \%$ and was similar between urban and rural participants ( $10 \%$ vs $6.4 \%$ respectively; $p=0.188$ ). Frequency of poor sleep quality was $50.3 \%$ and was similar in urban and rural groups (48.2\% vs $52.4 \%$ respectively, $\mathrm{p}=0.395$ ). Short SD represented $30.5 \%$ of the sample and was more frequent in the urban than rural group (36.1\% vs $24.8 \%$ respectively, $p=0.006)$. Short SD was significantly associated with diabetes (OR 2.62 , $95 \% \mathrm{Cl} 1.38-5.00$ ) while poor sleep quality was not significantly associated with diabetes. Poor sleep quality combined with short SD was strongly associated with diabetes (OR $2.67,95 \% \mathrm{Cl} 1.23-5.79$ ).

Conclusion there is a necessity to take into account sleep duration and quality in the management of diabetes

\section{Introduction}

Insufficient sleep duration and chronic sleep disturbances are known in develop countries as important public health problems. They are endemic in both adults and children (1-3) and they have important consequences on patients, given that they have a great impact on health, work, and quality of life (4-5). Recent population studies show that sleep deprivation and disorders affect many more people worldwide than had been previously reported. Data on the united states population show an average $6.8 \mathrm{~h}$ sleep duration per night which is $1.5 \mathrm{~h}$ less than that of 100 years ago (6). About $20-30 \%$ of the general population is estimated to have various types of sleep disorders and approximately 50-70 million Americans chronically suffer from disorders of sleep (7-9). Factors involved in the increasing burden of sleep disorders are rapid urbanization, increased prevalence of shift work and longer working days, prolonged commute times and activities of multiple leisure time (10). All these factors are of greatest increase in low-and-middle income countries, particularly in sub-Saharan Africa.

Numerous previous studies have associated habitual short sleep duration to important adverse 
cardio-metabolic outcomes, including weight gain, hypertension, obesity, diabetes, metabolic syndrome as well as other cardiovascular diseases (11-13). As Concerns diabetes mellitus, recent meta-analysis show a $30 \%$ increase in the risk of diabetes in participants with short sleep duration (14-15). It had also been demonstrated in healthy adults that sleep restriction results in increased insulin resistance (16) and decreased insulin sensitivity (17). Poor sleep quality known as insomnia has been also linked with type 2 diabetes mellitus and insulin resistance (18).

Although there are many evidences linking short sleep duration with diabetes, most of the studies did not examine the separate role of various sleep aspects in the development of diabetes. Considering the fact that various sleep disturbances often concurrently occur, it is important to tell the exact contribution of each sleep aspect as well as the association of sleep duration with global sleep quality. We therefore aimed to evaluate the separated and combined role of two aspects of sleep i.e. sleep duration and sleep quality on diabetes mellitus in the urban and rural Cameroonian population.

\section{Material And Methods}

\section{Study design and population}

This was a cross-sectional prospective survey conducted from February to March 2015 in a rural and urban population of the littoral region Cameroon. Urban participants were recruited in the Douala $V$ health district and rural participants were recruited in the Njombe-Penja health district. A total of 499 participants (249 in urban area and 250 in rural area) were randomly selected from the two communities using a three-stage cluster sampling with above-mentioned health districts as first stage, neighborhoods as second stage and households as third stage. Participants from both genders aged 18 years and older were included in the study. Other participants with the following characteristics were excluded: pregnant women, participants with previous diagnosis of obstructive sleep apnea syndrome or restless leg syndrome and those who were unable to cooperate with physical examination or interview due to mental disorder or physical disability. We finally included 499 participants; 249 participants in the rural area and 250 participants in the urban area.

\section{Data collection and parameters measurements}

Data were collected using a structured questionnaire administered to participants face to face. The following informations were collected: age, status of smoking and drinking, physical activity, fruits and vegetables consumption and profile of sleep. Status of smoking and drinking was evaluated from selfreported information. Physical activity was evaluated from responses to questions about type and frequency of physical exercise at work and during leisure time and was categorized into "active" ( $\geq 150$ $\mathrm{min} /$ week aerobic exercise such as

jogging, swimming, climbing, etc.) and "inactive". Fruit and vegetables intake was considered insufficient if consumption of either fruit or vegetables was $<5$ servings per day (19). Sleep quality was evaluated 
using the standard Pittsburgh Sleep Quality Index (PSQI), which is a widely used measure of sleep quality (20). This questionnaire is self-rated and evaluates sleep quality and disturbances over a 1-month period. It has 19 individual items with seven "component" scores. The scores of each item of the index vary between 0 and 3 . Total score of these seven components makes one score of $0-21$. Poor sleep quality was defined for a total score $>5$ (20). Sleep duration was evaluated from responses to relevant questions about the actual sleep duration every day in the past month and was classified into "short" ( $\leq 6 \mathrm{~h})$, "normal" (7 h $\leq$ sleep duration $\leq 8 \mathrm{~h}$ ) and "long" (>8 h) based on previous reports $(21-22)$.

\section{Parameters measurements}

Physical examination included blood pressure (BP), waist circumference (WC), weight and height. Body mass index (BMI) was calculated as weight in kilograms divided by the square of height in meter $\left(\mathrm{kg} / \mathrm{m}^{2}\right)$. Overweight was defined as $\mathrm{BMI} \geq 25 \mathrm{~kg} / \mathrm{m}^{2}$, and obesity as $\mathrm{BMI}>30 \mathrm{~kg} / \mathrm{m}^{2}$. Abdominal obesity was defined as $W C \geq 102 \mathrm{~cm}$ for men and $\geq 88 \mathrm{~cm}$ for women (23).

BP was measured after 15 minutes in the sitting position and in standardized conditions. Three consecutive BP measurements were taken at 5 minutes intervals using a validated automated sphygmomanometer (HEM-705 CP, Omron Corporation, Tokyo, Japan) with cuff's width adjusted to arm's circumference. A fourth measurement was obtained if the first three readings differed by $\geq 10$ $\mathrm{mmHg}$. The averages of the nearest three BP readings were considered in this study. Hypertension was defined as systolic $B P \geq 140 \mathrm{mmHg}$ and/or diastolic $B P \geq 90 \mathrm{mmHg}$, and/or ongoing antihypertensive medication (23).

Participants were instructed to fast for at least 8 hours overnight and fasting blood glucose (FBG) was determined using a glucometer (Accu-Chek Aviva, Roche, Mannheim, Germany). Diabetes was defined according to American Diabetes Association (ADA) criteria (24). Diabetes mellitus was defined as FBG $\geq$ $126 \mathrm{mg} / \mathrm{dL}$ ( $\geq 7.0 \mathrm{mmol} / \mathrm{L}$ ) and/or being on glucose-lowering medication(s),

\section{Statistical analysis}

Continuous variables were presented as mean \pm 1 standard deviation, and categorical data as percentages. Prevalence rates were presented with $95 \%$ confidence interval $(\mathrm{Cl})$. The significance of differences between proportions was assessed using Chi squared test (for categorical variables), whereas the significance of differences between continuous variables was assessed using Student's t test. Multivariable logistic regression was used to assess the association between diabetes and sleep quality and duration. Odd ratios were adjusted for age and gender. Statistical significance was set at $p<0.05$. All analyses were performed using SPSS 20 software (SSPS Inc, Chicago, Illinois, USA).

\section{Results}


Mean age of the sample was $36 \pm 12$ years with $39.1 \%$ of men. Sociodemographic, anthropometric, bioclinical parameters, as well as cardiovascular risk factors are presented in table 1 and compared between urban and rural participants. Quantitative variables are presented as mean \pm standard deviation and values in brackets represent percentages for qualitative variables. Mean age was slightly higher in rural than urban area $(p=0.037)$ and age was not significantly different between urban and rural participants $(p=0.971)$. Overweight/obesity, abdominal obesity, hypertension and diabetes mellitus; as well as their indicative parameters were not significantly different between urban and rural areas $(p>0.05)$. Alcohol consumption and physical activity were more frequent in rural area $(p=0.047$ and $p=$ 0.029 respectively) whereas fruits/vegetables consumption was more frequent in the urban area $(p=$ 0.0005).

\section{Table 1: characteristics of participants}

\begin{tabular}{rrrrr}
\hline & All & Urban & Rural & p \\
\hline Age, years & $36 \pm 12$ & $35 \pm 12$ & $37 \pm 11$ & 0.037 \\
Male gender, \% & $195(39.1)$ & $97(39.0)$ & $98(39.2)$ & 0.971 \\
Weight, kg & $72.8 \pm 15.4$ & $74.2 \pm 15.4$ & $71.5 \pm 15.4$ & 0.051 \\
Height, m & $1.66 \pm 0.08$ & $1.66 \pm 0.08$ & $1.66 \pm 0.08$ & 0.227 \\
BMI, kg/m] & $26.4 \pm 5.4$ & $26.8 \pm 5.7$ & $26.0 \pm 5.2$ & 0.111 \\
Overweight/obesity, \% & $268(53.7)$ & $144(57.8)$ & $124(49.6)$ & 0.079 \\
Waist circumference, \% & $86 \pm 13$ & $86 \pm 13$ & $86 \pm 13$ & 0.750 \\
Abdominal obesity, \% & $144(28.9)$ & $74(29.7)$ & $70(28.0)$ & 0.506 \\
Systolic BP, mmHg & $119 \pm 19$ & $119 \pm 19$ & $120 \pm 19$ & 0.326 \\
Diastolic BP, mmHg & $76 \pm 12$ & $75 \pm 13$ & $77 \pm 12$ & 0.195 \\
Hypertension, \% & $104(20.8)$ & $52(20.9)$ & $52(20.8)$ & 0.930 \\
Blood glucose, mg/dL & $105 \pm 33$ & $106 \pm 35$ & $104 \pm 30$ & 0.506 \\
Diabetes, \% & $41(8.2)$ & $25(10.0)$ & $16(6.4)$ & 0.188 \\
Smoking, \% & $36(7.2)$ & $15(6.0)$ & $21(8.4)$ & 0.394 \\
Alcohol, \% & $116(23.2)$ & $48(19.3)$ & $68(27.2)$ & 0.047 \\
Physical activity, \% & $323(64.7)$ & $149(59.8)$ & $174(69.6)$ & 0.029 \\
Sleep duration, h & $6.3 \pm 1.4$ & $6.1 \pm 1.4$ & $6.6 \pm 1.4$ & 0.0002 \\
PSQI global score & $6.1 \pm 2.9$ & $6.1 \pm 3.1$ & $6.1 \pm 2.6$ & 0.989 \\
\hline fruits/ vegetables, \% & $120(24.0)$ & $77(30.9)$ & $43(17.2)$ & 0.0005 \\
Phy & & & &
\end{tabular}


BMI: body mass index; BP: Blood pressure; PSQI: Pittsburgh sleep quality index

Figure 1 and figure 2 present the distribution of Pittsburg Sleep Quality Index (PSQI) score and subjective sleep duration (SD) among participants. Data are compared between urban and rural participants.

Frequency of poor sleep quality (PSQI score > 5) was $50.3 \%$ and was not significantly different between urban and rural participants ( $48.2 \%$ vs $52.4 \%$ respectively; $p=0.395)$. Participants with short sleep duration (sleep duration $\leq 6 \mathrm{~h}$ ) represent $30.5 \%$ of the sample. Those with sleep duration between $7-8 \mathrm{~h}$ and $>8 \mathrm{~h}$ represent $51.7 \%$ and $17.8 \%$ respectively. Frequency of short sleep duration in urban area was $36.1 \%$ and was significantly higher than rural area $(24.8 \%) ; p=0.006$.

\section{Figure 1: distribution of PSQI score in the sample}

\section{Figure 2: distribution of sleep duration in the sample}

Table 2 present the association between sleep quality and duration with diabetes. Data are presented as counts and percentages of participants with diabetes in each group. Crude OR have been calculated and adjusted for age and sex.

In the whole sample, frequency of diabetes was significantly higher in participants with SD $\leq 6 \mathrm{~h}$ compared to those with $S D>6 \mathrm{~h}(\mathrm{p}<0.001)$. Although the frequency of diabetes was higher in participants with poor sleep quality (PSQI > 5) when compared to those with PSQI $\leq 5$ ( $10 \%$ vs $6.5 \%$ respectively), the difference was not significant $(p<0.05)$. When combining sleep quality with sleep duration, participants with normal sleep quality associated with poor sleep duration (PSQI $\leq 5+\mathrm{SD} \leq 6 \mathrm{~h}$ ) and those with poor sleep quality associated with poor sleep duration (PSQI $>5+$ SD $\leq 6 h$ ) had a higher risk of diabetes compared to those with normal sleep quality and duration. Results were nearly the same in urban the area but no significant association has been found in the rural area. After adjustment for age and sex, we found in the whole sample a significant association of short sleep duration with diabetes (OR $2.5395 \% \mathrm{Cl} 1.32-$ $4.85 \mathrm{p}<0.01)$. Associations of short sleep duration with poor and normal sleep quality were also significantly associated with diabetes (OR: $4.1295 \% \mathrm{Cl} 1.18-14.4 \mathrm{p}<0.05$ and OR $2.6795 \% \mathrm{Cl} 1.22-5.81$ $\mathrm{p}<0.05$ respectively).

\section{Table 2: relationship between diabetes with sleep quality and sleep duration in the sample}




\section{n (\%)}

OR (95\% CI)

AOR (95\% CI)

\begin{tabular}{|c|c|c|c|c|}
\hline \multicolumn{5}{|c|}{ All } \\
\hline \multirow[t]{2}{*}{ SD } & $\mathrm{SD}>6 \mathrm{~h}$ & $20(5.8)$ & Ref & Ref \\
\hline & $\mathrm{SD} \leq 6 \mathrm{~h}$ & $21(13.8)$ & $2.62(1.38-5.00) * * *$ & $2.53(1.32-4.85)^{* *}$ \\
\hline \multirow[t]{2}{*}{ PSQI Score } & $\mathrm{PSQI} \leq 5$ & $16(6.5)$ & Ref & Ref \\
\hline & PSQI > 5 & $25(10.0)$ & $1.60(0.83-3.08)$ & $1.68(0.87-3.25)$ \\
\hline \multirow[t]{5}{*}{$\mathrm{PSQI}+\mathrm{SD}$} & $\mathrm{PSQI} \leq 5+\mathrm{SD}>6 \mathrm{~h}$ & $12(5.3)$ & Ref & Ref \\
\hline & $\mathrm{PSQI}>5+\mathrm{SD}>6 \mathrm{~h}$ & $8(6.7)$ & $1.28(0.51-3.22)$ & $1.41(0.55-3.56)$ \\
\hline & $\mathrm{PSQI} \leq 5+\mathrm{SD} \leq 6 \mathrm{~h}$ & $4(19.0)$ & $4.22(1.23-14.49) *$ & 4.12 (1.18- 14.4)* \\
\hline & $\mathrm{PSQI}>5+\mathrm{SD} \leq 6 \mathrm{~h}$ & $17(13.0)$ & 2.67 (1.23- 5.79)* & $2.67(1.22-5.81)^{*}$ \\
\hline & Urban & & & \\
\hline \multirow[t]{2}{*}{ SD } & $\mathrm{SD}>6 \mathrm{~h}$ & $10(6.3)$ & Ref & Ref \\
\hline & $S D \leq 6 h$ & 15 (16.7) & $2.98(1.28-6.95) *$ & 3.02 (1.29- 7.10)* \\
\hline \multirow[t]{2}{*}{ PSQI Score } & $\mathrm{PSQI} \leq 5$ & $10(7.8)$ & Ref & Ref \\
\hline & PSQI > 5 & $15(12.5)$ & $1.70(0.73-3.95)$ & $1.77(0.76-4.15)$ \\
\hline \multirow[t]{5}{*}{ PSQI + SD } & $\mathrm{PSQI} \leq 5+\mathrm{SD}>6 \mathrm{~h}$ & $7(6.2)$ & Ref & Ref \\
\hline & $\mathrm{PSQI}>5+\mathrm{SD}>6 \mathrm{~h}$ & $3(6.5)$ & $1.06(0.26-4.28)$ & $1.13(0.28-4.60)$ \\
\hline & $\mathrm{PSQI} \leq 5+\mathrm{SD} \leq 6 \mathrm{~h}$ & $3(18.8)$ & $3.49(0.80-15.2)$ & $3.61(0.81-15.9)$ \\
\hline & $\mathrm{PSQI}>5+\mathrm{SD} \leq 6 \mathrm{~h}$ & $12(16.2)$ & 2.93 (1.10- 7.84)* & $3.03(1.12-8.16) *$ \\
\hline & Rural & & & \\
\hline \multirow[t]{2}{*}{ SD } & $\mathrm{SD}>6 \mathrm{~h}$ & $10(5.3)$ & Ref & Ref \\
\hline & $S D \leq 6 h$ & $6(9.7)$ & $1.91(0.66-5.48)$ & $1.72(0.59-5.04)$ \\
\hline \multirow[t]{2}{*}{ PSQI Score } & $\mathrm{PSQI} \leq 5$ & $6(5.0)$ & ref & Ref \\
\hline & PSQI > 5 & $10(7.6)$ & $1.56(0.55-4.42)$ & $1.61(0.56-4.63)$ \\
\hline \multirow[t]{4}{*}{ PSQI + SD } & $\mathrm{PSQI} \leq 5+\mathrm{SD}>6 \mathrm{~h}$ & $5(4.4)$ & Ref & Ref \\
\hline & $\mathrm{PSQI}>5+\mathrm{SD}>6 \mathrm{~h}$ & $5(6.8)$ & $1.58(0.44-5.66)$ & $1.75(0.48-6.35)$ \\
\hline & $\mathrm{PSQI} \leq 5+\mathrm{SD} \leq 6 \mathrm{~h}$ & $1(20.0)$ & $5.45(0.51-58.2)$ & $4.66(0.43-50.8)$ \\
\hline & $\mathrm{PSQI}>5+\mathrm{SD} \leq 6 \mathrm{~h}$ & $5(8.8)$ & $2.10(0.58-7.56)$ & $1.98(0.54-7.25)$ \\
\hline
\end{tabular}


SD: sleep duration; OR: odd ratio; AOR: adjusted odd ratio (adjusted for age and sex); CI: confidence interval; $* \mathrm{p}<0.05 ; * * \mathrm{p}<0.01 ; * * * \mathrm{p}<0.001$

\section{Discussion}

In this cross-sectional comparative study, we found some important results underlying the role of sleep quality on diabetes mellitus in urban and rural communities in the Cameroonian population. Mean sleep duration in the sample was $6.3 \mathrm{~h}$ and was significantly higher in rural than urban participants, as well as frequency of short sleep duration was significantly higher in urban than rural area. Contrary to all expectations, frequency of poor sleep quality was similar in urban and rural area (25). As expected, short sleep duration was significantly associated with the risk of diabetes in the whole sample. Although poor sleep quality was not significantly associated with diabetes, a combination of short sleep duration with poor sleep quality was significantly associated with diabetes. Short sleep duration $(\leq 6 \mathrm{~h})$ as well as poor sleep quality ( $\mathrm{PSQI}>5$ ) has been described by many authors as a predictive factor of comorbidities such as hypertension (26), metabolic syndrome (27) and overweight/obesity (28).

Frequency of poor sleep quality found in our study was relatively high compared to other sub-Saharan African countries. A large study conducted on more than 40000 adults from 8 African and Asian countries shows that prevalence of poor sleep quality varies from $8.3 \%$ to $12.7 \%$ in Kenya, Ghana and Tanzania. In South Africa, the prevalence was $31.3 \%$ in female and $27.3 \%$ in male (29). On the contrary, our results are similar those of Tai et al. who found a prevalence of $46.6 \%$ on the Taiwanese population (30).

There is a bundle of literature on the association of diabetes mellitus with sleep disorders using different sleep quality evaluation tools. Many authors have demonstrated a high prevalence of sleep disorders in participants with diabetes mellitus compared to those without diabetes. Using the Pittsburg Sleep Quality Index (PSQI), Fiorentini and colleagues reported a higher prevalence of diabetes mellitus in participants with poor sleep quality (19.4\%) compared to those with good sleep quality (8.8\%) (31). More recently, Zubair and colleagues found that PSQI global score as well as PSQI score $>5$ were higher in participants with diabetes compared to those without (32). We found in our study a 2.62 folds increase in the risk of diabetes in patients with short sleep duration (SD $\leq 6 \mathrm{~h}$ ) compared to those with normal sleep duration ( $S D \geq 6 \mathrm{~h}$ ) which was consistent with results of Anothaisintawee et al who showed that short sleep duration is predictive of diabetes with relative risk of $1.18(95 \% \mathrm{Cl} 1.10-1.26)$ (33). Short sleep duration has also been shown to be a strongly predictive factor of prediabetes. Engeda et al, found that individuals who reported short sleep duration had a 2.06 higher odds of prediabetes $(95 \% \mathrm{Cl} 1.00-4.22)$ compared to individuals who reported $7 \mathrm{~h}$ of sleep (34).

Mechanisms underlying the association of diabetes and glucose homeostasis with sleep disorders are not well established. These include higher evening cortisol levels, increased sympathic nervous system activity, and catecholamine production, as well as higher levels of inflammatory factors, which promote insulin resistance such as interleukin (IL) $-1 \beta, I L-6, I L-17$, and CRP (35). In addition, several short term 
studies show that sleep fragmentation or restriction lead to insulin resistance (36-37) which appears to play a key role in the pathophysiology of diabetes. Although frequency of diabetes in our study was higher in participants with poor sleep quality (PSQI > 5) compared to those with normal sleep quality ( $10 \%$ vs $6.5 \%$ respectively), the association of sleep quality and diabetes was not significant. Hung and colleagues show that hyperglycemia is an independent determinant of the global PSQI score (27). In addition, other studies show that poor sleep quality is associated with poor glycemic control and the development of type 2 diabetes $(14,18)$.

When combining sleep duration with sleep quality, we found that participants with short sleep duration and normal sleep quality as well as those with short sleep duration and quality had a higher risk of diabetes compared to those with normal sleep duration and quality $(\mathrm{OR} 4.22,95 \% \mathrm{Cl} 1.23-14.49$ and $\mathrm{OR}$ $2.67,1.23-5.79$ respectively). The higher odd of having diabetes when combining sleep duration and quality than when taken separately emphasize the necessity of considering these two parameters together in the management of cardiovascular disorders. Our result was corroborated by some previous studies aiming to explore the interaction of sleep duration and sleep quality on impaired fasting glucose (13), hypertension (26) and cardiovascular events (38) which also indicated an additive effect of them. However, our work is the first report on the interaction of sleep quality and duration on diabetes in the Cameroonian population.

Our study presents several limitations as follow: The sample was collected in two local urban and rural communities and could not be representative of the Cameroonian population. As we conducted a crosssectional survey, we could not conclude on the causal relation between sleep disorders and diabetes in our study. We could not measure primary sleep disorders such as Obstructive Sleep Apnea Syndrome and Rest Leg Syndrome which can have an unpredictable impact on our results.

\section{Conclusion}

Our cross-sectional study shows a high prevalence of short sleep duration and poor sleep quality in an urban and rural community in Cameroon. It also demonstrated a significant impact of short sleep duration as well as combination of short sleep duration and poor sleep quality on diabetes prevalence. Diabetes was not significantly associated with poor sleep quality; although diabetes prevalence was more frequent in participants with poor sleep quality compared to those with normal sleep quality.

\section{Abbreviations}

BMl: body mass index

BP: blood pressure

Cl: confidence interval

FBG: fasting blood glucose 
OR: odd ratio

PSQI: Pittsburg sleep quality index

SD: sleep duration

WC: waist circumference

\section{References}

1. Bonnet MH, Arand DL. We are chronically sleep deprived. Sleep 1995; 18:908-11

2. Knutson KL, Van Cauter E, Rathouz PJ, DeLeire T, Lauderdale DS. Trends in the prevalence of short sleepers in the USA: 1975-2006. Sleep 2010; 33(1):37-45.

3. Leger D, Roscoat E, Bayon V, Guignard R, Paquereau J, Beck F. Short sleep in young adults: Insomnia or sleep debt? Prevalence and clinical description of short sleep in a representative sample of 1004 young adults from France. Sleep Med. 2011;12(5):454-462.

4. Brown WD. Insomnia: Prevalence and daytime consequences. In: Lee-Chiong T, editor. Sleep: A Comprehensive Handbook. Hoboken, New Jersey: John Wiley and Sons; 2006. pp. 93-98.

5. Trenell MI, Marshall NS, Rogers NL. Sleep and metabolic control: waking to a problem? Clin. Exp. Pharmacol. Physiol. 2007;34:1-9.

6. National Sleep Foundation (NSF). Sleep in America Poll 2003. Washington, DC: National Sleep Foundation; 2003

7. Mitler M, Carskadon MA, Czeisler CA, Dement WC, Dinges DF, GraeberRC. Catastrophes, sleep, and public policy: Consensus report. Sleep 1988;11:100-9.

8. Gilling JC. Are sleep disturbances risk factors for anxiety, depressive and addictive disorders? Acta Psychiatr Scand Suppl 1998;393:39-43.

9. Colten HR, Altevogt BM, editors. Sleep disorders and sleep deprivation: An unmet public health problem. Washington DC: National Academies Press; 2006. p. 67-209.

10. Marjollet A., Weiszenstein M., Henri M., Thomas A., Ribuot D., et al, The impact of sleep disorders on glucose metabolism: endocrine and molecular mechanisms, Diabetol. Metab. Syndr. 2015;25:7-25.

11. Logue EE, Scott ED, Palmieri PA, Dudley P. Sleep duration, quality, or stability and obesity in an urban family medicine center. J. Clin. Sleep Med. 2014; 10:177-182.

12. Okubo N, Matsuzaka M, Takahashi I, Sawada K, Sato S, Akimoto N, Umeda T, Nakaji S. Relationship between self-reported sleep quality and metabolic syndrome in general population. BMC Public Health 2014;14:562.

13. Lou P, Chen P, Zhang L, Zhang P, Chang G, Zhang N, Li T, Qiao C. Interaction of sleep quality and sleep duration on impaired fasting glucose: A population-based cross-sectional survey in China. BMJ Open 2014, 4. 
14. Cappuccio FP, D’Elia L, Strazzullo P, Miller MA. Quantity and quality of sleep and incidence of type 2 diabetes: a systematic review and meta-analysis. Diabetes Care. 2010; 33:414-420.

15. Holliday EG, Magee CA, Kritharides L, Banks E, Attia J. Short sleep duration is associated with risk of future diabetes but not cardiovascular disease: a prospective study and meta-analysis. PLoS One. 2013; 8:e82305.doi: 10.1371/journal.pone.0082305

16. Broussard JL, Ehrmann DA, Van Cauter E, Tasali E, Brady MJ. Impaired insulin signaling in human adipocytes after experimental sleep restriction: a randomized, crossover study. Ann Intern Med. 2012; 157:549-557.

17. Buxton OM, Pavlova M, Reid EW, Wang W, Simonson DC, Adler GK. Sleep restriction for 1 week reduces insulin sensitivity in healthy men. Diabetes. 2010; 59:2126-33.

18. Knutson KL, Van Cauter E, Zee P, Liu K, Lauderdale DS. Cross-sectional associations between measures of sleep and markers of glucose metabolism among subjects with and without diabetes: the Coronary Artery Risk Development in Young Adults (CARDIA) Sleep Study. Diabetes Care. 2011; 34(5):1171-6.

19. World Health Organization (WHO). Global Status Report on noncommunicable diseases 2010. Geneva: World Health Organization, 2011.

20. Buysse DJ, Reynolds CF 3rd, Monk TH, Berman SR, Kupfer DJ. The Pittsburgh Sleep Quality Index: a new instrument for psychiatric practice and research. Psychiatry Res 1989; 28: 193-213.

21. Martica, H. H.; Muldoon, M. F.; Jennings, J. R.; Buysse, D. J.; Flory, J. D.; Manuck, S. B. Self-reported sleep duration is associated with the metabolic syndrome in midlife adults. Sleep 2008; 31: 635643.

22. James EG, Heymsfield SB, Boden-Albala B, Buijs RM, Kreier F, Pickering TG, Rundle AG, Zammit GK, Malaspina D. Short sleep duration as a risk factor for hypertension analyses of the first national health and nutrition examination survey. Hypertension 2006; 47: 833-839

23. Mancia G, Fagard R, Narkiewicz K, et al. 2013 ESH/ESC hypertension guidelines for the Management of Arterial Hypertension: the Task Force for the Management of Arterial Hypertension of the European Society of Hypertension (ESH) and of the European Society of cardiology (ESC). Eur Heart J. 2013; 34:2159-219.

24. American Diabetes Association (ADA). Standards of medical care in diabetes-2010. Diabetes Care 2010; 33:11-61.

25. Hsu YW, Ho CH, Wang JJ, Hsieh KY, Weng SF, Wu MP. Longitudinal trends of the healthcare-seeking prevalence and incidence of insomnia in Taiwan: an 8-year nationally representative study. Sleep Med. 2013;14:843-9.

26. Lu K, Chen J, Wang L, Wang C, Ding R, Wu S Hu D. Association of Sleep Duration, Sleep Quality and Shift-Work Schedule in Relation to Hypertension Prevalence in Chinese Adult Males: A CrossSectional Survey. Int. J. Environ. Res. Public Health 2017; 14: 210; doi:10.3390/ijerph14020210

27. Hung H-C, Yang Y-C, Ou H-Y, Wu J-S, Lu F-H, Chang CJ. The Association between Self-Reported Sleep Quality and Metabolic Syndrome. PLoS ONE 2013;8(1):e54304. doi:10.1371/journal.pone.0054304 
28. Ford ES, Li C, Wheaton AG, Chapman DP, Perry GS, Crof JB. Sleep duration and body mass index and waist circumference among US adults. Obesity 2014; 22(2):598-607.

29. Stranges S, Tigbe W, Gomez-Olivé FX, Thorogood M, Kandala NB. Sleep problems: an emerging global epidemic? Finding from the INDEPTH WHO-SAGE study among more than 40,000 older adults from 8 countries across Africa and Asia. Sleep Med Rev. 2012; 35(8): 1173-81.

30. Tai SY, Wang WF, Yang YH. Current status of sleep quality in Taiwan: a nationwide walk-in survey. Ann Gen Psychiatry 2015 ; 14:36 DOI 10.1186/s12991-015-0078-7

31. Fiorentini A, Valente R, Perciaccante A, Tubani L. Sleep's quality disorders in patients with hypertension and type 2 diabetes mellitus. Int J Cardiol. 2007; 114(2):50-2.

32. Zubair U, Majid F, Siddiqui A A, Zubair Z. Sleep Abnormalities Among Patients With and Without Diabetes Using Pittsburg Sleep Quality Index and Epworth Sleepiness Scale. Cureus 2018; 10(2): e2151. DOI 10.7759/cureus.2151

33. Anothaisintawee T, Reutrakul S, Van Cauter E, Thakkinstian A. Sleep disturbances compared to traditional risk factors for diabetes development: systematic review and meta-analysis. Sleep Med Rev. 2015; 30:11-24.

34. Engeda J, Mezuk B, Ratliff S, Ning Y. Association between duration and quality of sleep and the risk of pre-diabetes: evidence from NHANES. Diabet Med. 2013; 30(6):676-80.

35. Knutson KL. Sociodemographic and cultural determinants of sleep deficiency: implications for cardiometabolic disease risk. Soc Sci Med 2013; 79:7-15.

36. Tasali E, Leproult R, Ehrmann DA, Van Cauter E. Slow-wave sleep and the risk of type 2 diabetes in humans. Proc Natl Acad Sci USA 2008; 105: 1044-1049

37. Stamatakis KA, Punjabi NM. Effects of sleep fragmentation on glucose metabolism in normal subjects. Chest 2010; 137: 95-101.

38. Hoevenaar-Blom MP, Spijkerman AM, Kromhout D, van den Berg JF, Verschuren WM. Sleep duration and sleep quality in relation to 12-year cardiovascular disease incidence: The MORGEN study. Sleep 2011; 34: 1487-92.

\section{Declarations}

\section{Ethics approval and consent to participate:}

all participants signed an informed consent and Ethical approval of the study protocol was granted by the Institutional Review Board of Douala University (Authorization N ${ }^{\circ}$ CE-UD/088/02/2015/T)

\section{Consent for publication:}

Not applicable 


\section{Availability of data and materials:}

The datasets used and/or analyzed during the current study are available from the corresponding author on reasonable request

\section{Competing interests:}

None

\section{Funding:}

personal funding

\section{Authors' contributions:}

DL and PVB designed the study protocol, planned analyses and corrected the manuscript. DL, TM, JND and ME contributed to data collection. ECBL led the statistical analyses, contributed data interpretation and wrote the first manuscript draft. MH, JPD, ML, HBM and WN contributed to data interpretation and the correction of the manuscript. All authors reviewed and approved the final manuscript draft.

\section{Acknowledgements:}

The authors express their grateful thanks to the survey officers, to all the participants to the survey, to ULB-Erasme Hospital and to the Faculty of Medicine and

Pharmaceutical Sciences of Douala University for continued support to epidemiological research on noncommunicable diseases in Cameroon.

\section{Figures}




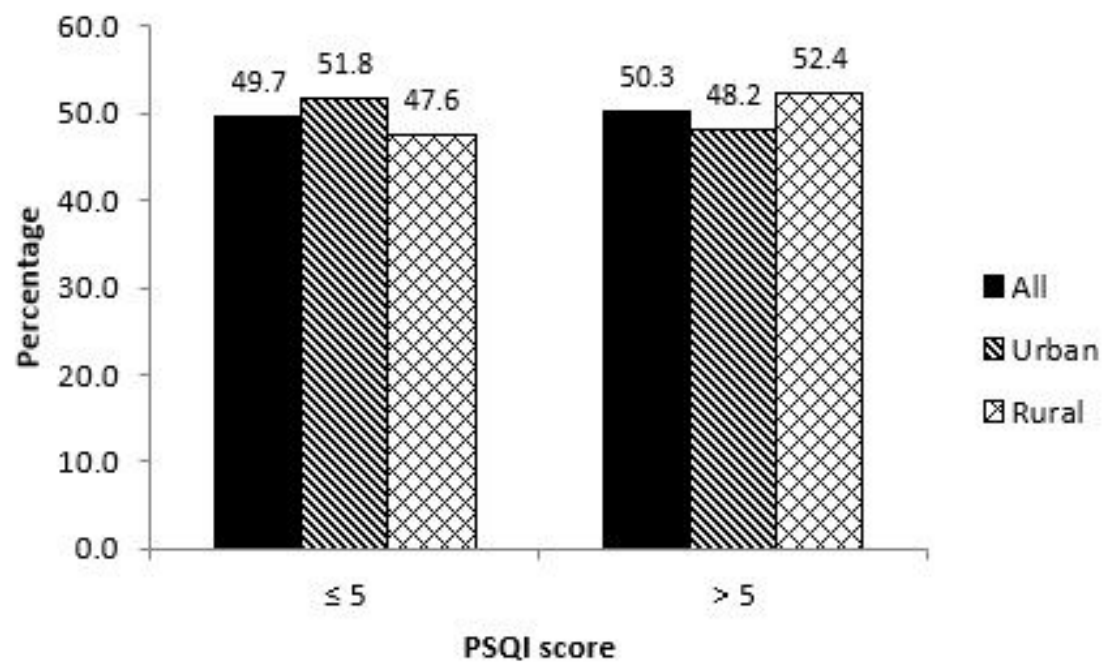

\section{Figure 1}

distribution of PSQI score in the sample

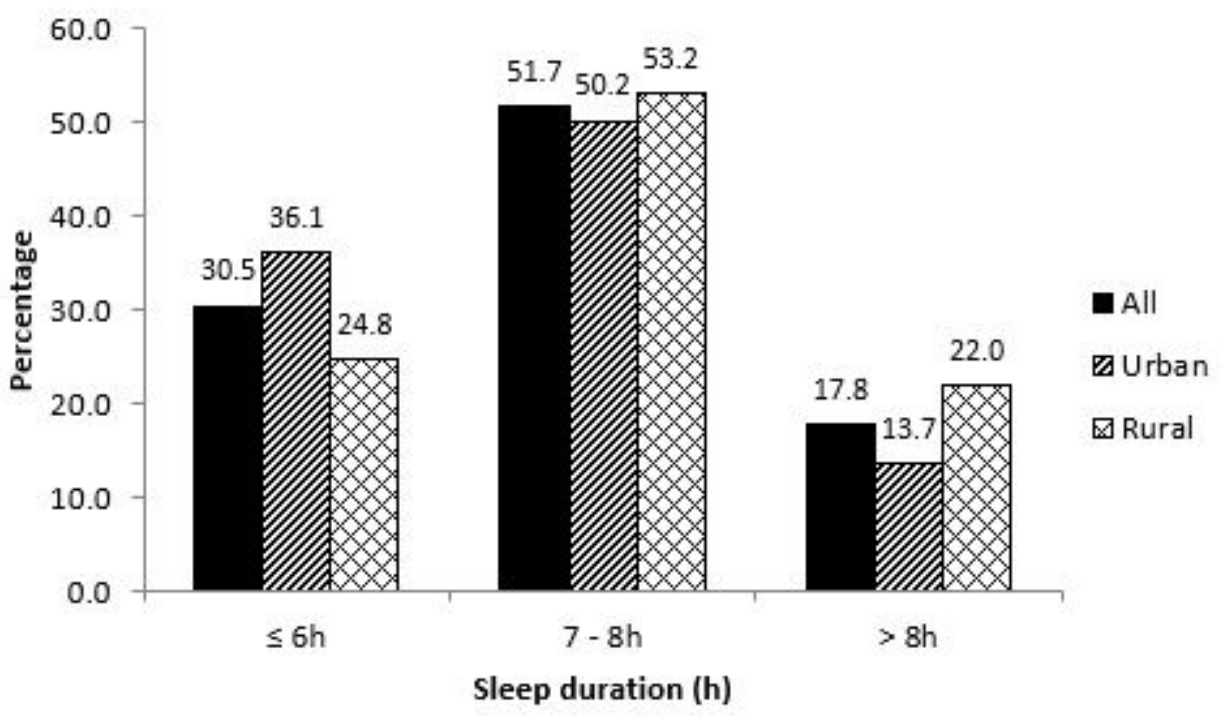

Figure 2

distribution of sleep duration in the sample 